\title{
Bradykinin improves postischaemic recovery in the rat heart: role of high energy phosphates, nitric oxide, and prostacyclin
}

\author{
Peili Zhu, Christian E Zaugg, David Simper, Pius Hornstein, Peter R Allegrini, \\ and Peter T Buser
}

\begin{abstract}
Objective: The aim was to define: (1) whether bradykinin administration during reperfusion improves postischaemic myocardial recovery; (2) whether high energy phosphate compounds are involved in the protective effects of bradykinin; and (3) whether bradykinin-induced release of prostacyclin and nitric oxide mediate the protective effects of bradykinin. Methods: In the Langendorff rat heart preparation, coronary flow, left ventricular developed pressure, and, using ${ }^{31} \mathrm{P}$ magnetic resonance spectroscopy, the high energy phosphate compounds phosphocreatine and $\beta$-ATP were assessed during $15 \mathrm{~min}$ of global ischaemia and $30 \mathrm{~min}$ of reperfusion. Administration of $10^{-7} \mathrm{M}$ bradykinin was started before ischaemia and maintained throughout the experiment (BK-pre). This was compared to $10^{-7} \mathrm{M}$ bradykinin given exclusively with reperfusion (BK-post). Then $10^{-7} \mathrm{M}$ bradykinin was given simultaneously with $10^{-4} \mathrm{M} \mathrm{N} \omega$-nitro-L-arginine-methyl ester (BK-LNAME) or $10^{-5} \mathrm{M}$ indomethacin (BK-indo). Results: In comparison to control hearts, BK-pre exerted a significant protective effect on the postischaemic recovery of coronary flow [71(5)\% v 43(4)\%, $\mathrm{P}<0.05]$, left ventricular pressure $[81(8) \% \vee 42(5) \%, \mathrm{P}<0.05]$, phosphocreatine $[105(4) \% \vee 67(8) \%, \mathrm{P}<0.05]$, and $\beta$-ATP $[78(9) \% v$ $48(7) \%, \mathrm{P}<0.05]$. With BK-post, recovery of coronary flow $[71(4) \% v 43(4) \%, \mathrm{P}<0.05]$ and left ventricular pressure $[78(4) \% \vee 42(5) \%, \mathrm{P}<0.05]$ significantly improved; however the recovery of phosphocreatine $[70(4) \%$ $v 67(8) \%$, NS] and $\beta$-ATP [58(2)\% v 48(7)\%, NS] was not different from control. When bradykinin and L-NAME or indomethacin was given the beneficial effects of bradykinin on ischacmic hearts were abolished. Conclusions: (1) Bradykinin improved postischaemic myocardial recovery when given before ischaemia or starting exclusively with reperfusion; (2) this was only partially related to a protective action on the high energy phosphate compounds during ischaemia; (3) the beneficial effects of bradykinin on ischaemic hearts are dependent from an unrestrained action of prostacyclin and nitric oxide.
\end{abstract}

Cardiovascular Research 1995;29:658-663

$\mathrm{C}$ Turrent therapy of acute myocardial infarction is aimed at early reperfusion by means of thrombolysis, angioplasty, and coronary bypass surgery in order to rescue myocardial tissue and to reduce ischaemic and reperfusion damage. A variety of drugs has been investigated for their ability to attenuate ischaemic myocardial damage and to improve postischaemic recovery. There is experimental evidence that angiotensin converting enzyme (ACE) inhibitors exert protective effects on the ischaemically threatened myocardium. ${ }^{12}$ Three properties of ACE inhibitors may contribute to this protective effect. First, ACE inhibitors reduce the conversion of angiotensin I to angiotensin II, one of the most potent vasoconstrictive peptides. ${ }^{3}$ Second, it has been proposed that some ACE inhibitors scavenge free oxygen radicals by the sulphydryl group. ${ }^{4}$ Third, ACE inhibitors reduce the bradykinin breakdown. ${ }^{5}$ The potential role of bradykinin in the protective effect of ACE inhibitors in the ischaemic heart was recently supported by the abolition of this protection after coadministration of a bradykinin antagonist. ${ }^{67}$

The kinin precursors are $\alpha$ globulins called kininogens. ${ }^{8}$ It has been shown that acute myocardial ischaemia is associated with a decrease in plasma kininogen and an increase in plasma kinins in rats. ${ }^{10}$ In humans, kinin levels in peripheral blood were found to increase soon after myocardial infarction. It was suggested that kinins released during myocardial infarction may have cardioprotective effects. " Furthermore, administration of bradykinin before the onset of ischaemia has been shown to improve postischaemic recovery of left ventricular performance and to attenuate the severity of reperfusion arrhythmias in rat hearts. ${ }^{6}$ However, it is not known whether the administration of bradykinin exclusively during reperfusion also leads to a beneficial effect. Furthermore, the mechanism behind the protective effects of bradykinin in ischaemic hearts is still unclear. It has been proposed that high energy phosphate compounds like ATP or phosphocreatine are involved in the protective effect of bradykinin. On the other hand, nitric oxide or prostacyclin may contribute to the protective effect of bradykinin because bradykinin could release these compounds.

Our first objective was therefore to determine whether bradykinin administration during reperfusion improves the recovery of the ischaemic heart. Our second was to determine whether high energy phosphate compounds are involved in the protective effect of bradykinin. Thirdly, we

Division of Cardiology, DIM, University Hospital, Petersgraben 4, 4031 Bascl, Switzerland: P Zhu, C E Zaugg, D Simper, P Hornstein, P T Buser; Biology Research Laboratories, CIBA Ltd, Basel Switzerland: P R Allegrini. Correspondence to Dr Buser. 
wanted to show whether bradykinin-induced release of prostacyclin or nitric oxide may mediate the protective effect of bradykinin.

\section{Methods}

\section{Perfused heart mode}

Male Sprague-Dawley rats weighing $250-330$ g were anaesthetised by injection of sodium pentobarbitone ( $30 \mathrm{mg} \cdot \mathrm{kg}^{-1}$ intraperitoneally) and heparinised (1000 IU $\cdot \mathrm{kg}^{-1}$ intraperitoneally). The hearts were excised rapidly through a midling sternotomy and perfused at $37^{\circ} \mathrm{C}$ according to a modified Langendorff method. ${ }^{12}$ All hearts were perfused with a constant perfusion pressure of $90 \mathrm{~cm} \mathrm{H}_{2} \mathrm{O}$. As perfusate a modified Krebs-Henseleit solution was used containing (in mmol-litre ${ }^{-1}$ ): $\mathrm{NaCl}$ $117, \mathrm{KCl} 4.3, \mathrm{CaCl}_{2} 2.0, \mathrm{MgCl}_{2} 1.2, \mathrm{KH}_{2} \mathrm{PO}_{4} 0.1, \mathrm{NaHCO}_{3} 25$, EDTA 0.5 , and glucose 15 , with insulin 10 units-litre ${ }^{-1}, \mathrm{pH} \mathrm{7.4}$, and gassed with $95 \% \mathrm{O}_{2}$ and $5 \% \mathrm{CO}_{2} \cdot{ }^{12}$ The heart was maintained at $37^{\circ} \mathrm{C}$ by a thermostatic system throughout the experiment. A Grass SD 5 pulse generator was used throughout the experiment to pace the hearts at a constant frequency which was $20 \%$ above the spontaneous heart rate [264(SEM 34) beats- $\left.\mathrm{min}^{-1}\right]{ }^{13}$ Eleven percent of all hearts were rejected because of delayed preparation resulting in a depressed left ventricular pressure development during the equilibrium phase or persistent ventricular fibrillation following postischaemic reperfusion. The number of rejected hearts was not significantly different between the treatment groups. All animal experiments were performed according to the guidelines of the ethics committee on animal research of the University Basel, Switzerland.

\section{Physiological measurements}

Left ventricular pressure was obtained from a cannula inserted through the left atrial appendage into the left ventricular cavity and connected to a pressure transducer and a multitrace recorder. Left ventricular developed pressure was calculated as left ventricular systolic pressure minus left ventricular diastolic pressure. Coronary flow was determined by collecting the effluent from the right ventricular outflow tract. ${ }^{14}$

\section{"Phosphorus magnetic resonance spectroscopy (MRS)}

${ }^{31} \mathrm{P}$ MRS of the isolated beating rat heart was obtained on a 4.7 Tesla horizontal $300 \mathrm{~mm}$ bore magnet (Bruker Spectrospin B-C 47/30). ${ }^{31} \mathrm{P}$ spectra were obtained at $81.0 \mathrm{MHz}$ with a spectral width of $5000 \mathrm{~Hz}$. The pulse angle was $45^{\circ}$ and the pulse duration was $50 \mu$ s with a repetition time of $1.0 \mathrm{~s}$. Three hundred transients were accumulated at 5 min intervals. The signal to noise ratio was $20: 1$ for phosphocreatine. For each spectrum, the characteristic peaks for phosphocreatine, the $\alpha$, $\beta$, and $\gamma$ phosphate group of ATP, inorganic phosphate, and sugar monophosphates were identified..$^{15}$ After definition of the baseline, each spectrum and the corresponding areas were numerically integrated. Chemical shifts were referred to the resonance position of $\mathrm{PCr} .^{16}$ The intracellular $\mathrm{pH}\left(\mathrm{pH}_{\mathrm{i}}\right)$ was calculated from the chemical shift of the inorganic phosphate peak relative to phosphocreatine. ${ }^{17}$
Experimental protocol

Following $20 \mathrm{~min}$ drug-free perfusion under control conditions, allowing the hearts to stabilise (equilibrium period), the drugs were added to the perfusate for $30 \mathrm{~min}$ (preischaemic treatment period). Global ischaemia was then induced by stopping perfusion for $15 \mathrm{~min}$ (ischaemic period). The stopcock was re-opened and the heart reperfused under control condition for $30 \mathrm{~min}$ (reperfused period) (fig 1). Left ventricular pressure was continuously monitored, coronary flow was measured at $5 \mathrm{~min}$ intervals, and ${ }^{31} \mathrm{P}$ spectra were recorded during 5 min periods.

The rats were randomly assigned to seven groups: (1) untreated control group (control, $\mathrm{n}=8$ ); (2) $10^{-7} \mathrm{M}$ bradykinin given preischaemically throughout the experiment (BK-pre, $\mathrm{n}=6$ ); (3) $10^{-9} \mathrm{M}$ bradykinin given postischaemically at the beginning of reperfusion (BK-post, $\mathrm{n}=6$ ); (4) $10^{4} \mathrm{M}$ N $\omega$-nitro-L-arginine methyl ester (LNAME) given throughout the experiment (L-NAME, $n=5$ ); (5) $10^{-5} \mathrm{M}$ indomethacin given throughout the experiment (Indo, $n=5$ ); $(6) 10^{-7} \mathrm{M}$ bradykinin and $10^{-4} \mathrm{M} \mathrm{L-NAME}$ given throughout the experiment (BKLNAME, $\mathrm{n}=7) ;(7) 10^{-7} \mathrm{M}$ bradykinin and $10^{-5} \mathrm{M}$ indomethacin given throughout the experiment (BK-indo, $n=6$ ) (fig 1).

Drugs

Bradykinin, L-NAME, and indomethacin were from Sigma.

\section{Statistical analysis}

Results are reported as mean(SEM). The percent recovery was obtained compared to the values before ischaemia. Statistical analysis between groups was performed with the one factor ANOva Scheffe F test Statistical analysis in the same group between equilibrium and preischaemic treatment period was performed with a paired Student's $\imath$ test. For all statistical analysis, the null hypothesis was rejected at the $95 \%$ level, considering $\mathrm{P}<0.05$ significant

\section{Results}

\section{Absolute values}

At the end of the equilibrium phase, during which the hearts were allowed to stabilise, no significant changes were observed for coronary flow, left ventricular pressure, phosphocreatine, $\beta$-ATP, and $\mathrm{pH}_{\mathrm{i}}$ in any of the groups. There were no significant differences between the control group and all treatment groups. In the table absolute values of coronary flow and left ventricular pressure at the end of the equilibrium phase, the effects of bradykinin, L-NAME, and indomethacin on these variables, and the values after $30 \mathrm{~min}$ of postischaemic reperfusion are presented for all groups.

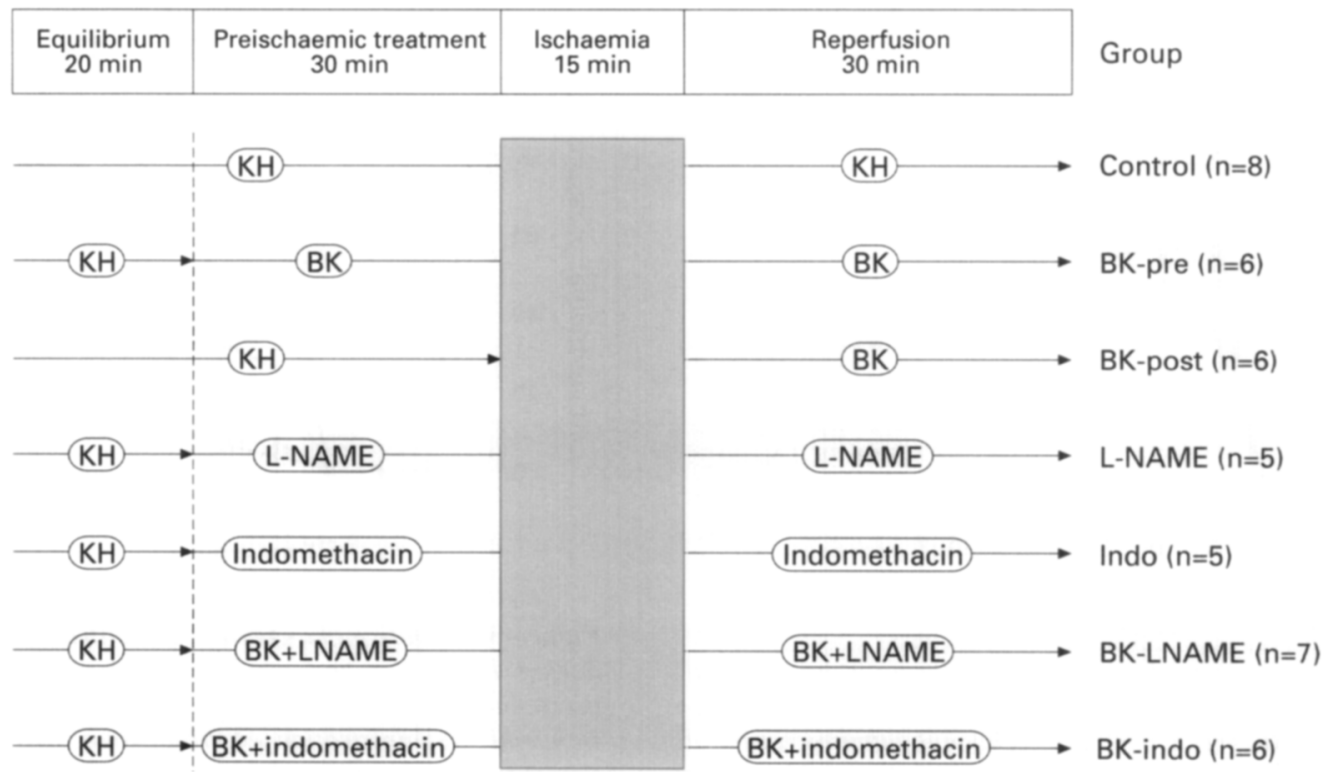

Figure 1 The experimental protocol. Control group: Krebs-Henseleit solution throughout the experiment; BK-pre: bradykinin given preischaemically throughout the experiment; BK-post: bradykinin given postischaemically at the beginning of reperfusion; L-NAME: L-NAME given throughout the experiment; Indo: indomethacin given throughout the experiment; BK-LNAME: bradykinin and L-NAME given throughout the experiment; $B K$-indo: bradykinin and indomethacin given throughout the experiment. 
Effect of bradykinin, L-NAME, and indomethacin on haemodynamic variables after 20 min of equilibrium, 30 min of preischaemic treatment, and $30 \mathrm{~min}$ of reperfusion. Values are means(SEM).

\begin{tabular}{|c|c|c|c|c|c|c|}
\hline & \multicolumn{3}{|c|}{ Coronary flow $\left(\mathrm{ml} \cdot \mathrm{min}^{-1}\right)$} & \multicolumn{3}{|c|}{$L V P(m m H g)$} \\
\hline & Equilibrium & Drug & Reperfusion & Equilibrium & Drug & Reperfusion \\
\hline Control $(n=8)$ & $10.0(0.3)$ & $10.0(0.3)$ & $4.3(0.4)$ & $81(2.6)$ & $80(3.0)$ & $33(3.7)$ \\
\hline BK-post $(n=6)$ & $10.0(0.2)$ & $10.0(0.2)$ & $7.1(0.2)^{*}$ & $75(1.4)$ & $74(1.6)$ & $58(3.6)^{*}$ \\
\hline BK-pre $(n=6)$ & $10.0(0.2)$ & $13.1(0.8)^{* \dagger}$ & $9.4(1.2)^{*}$ & $76(1.1)$ & $91(3.3)^{*+1}$ & $75(8.8)^{*}$ \\
\hline L-NAME $(n=5)$ & $10.4(0.3)$ & $5.5(0.2)^{* t}$ & $3.8(0.2)$ & $80(0.9)$ & $80(0.8)$ & $19(4.7)^{*}$ \\
\hline Indo $(\mathrm{n}=5)$ & $10.3(0.5)$ & $10.6(0.4)$ & $5.4(0.2)$ & $82(0.5)$ & $82(0.7)$ & $40(6.8)$ \\
\hline BK-LNAME $(n=7)$ & $10.2(0.6)$ & $9.5(0.6)$ & $5.6(0.2)$ & $79(1.6)$ & $89(2.1)^{*+}$ & $33(7.6)$ \\
\hline
\end{tabular}

LVP = left ventricular developed pressure; BK-post = postischaemic administration of bradykinin; BK-pre = preischaemic administration of bradykinin I,-NAMF = administration of L-NAMF; Indo = administration of indomethacin; BK-INAMF, = simultaneous administration of bradykinin and $1 .-$ NAMF; $\mathrm{BK}$-indo = simultaneous administration of bradykinin and indomethacin

$* \mathrm{P}<0.05 v$ control group; $\uparrow \mathrm{P}<0.05 v$ respective equilibrium period.

Percent changes during ischaemia and reperfusion

During the 20 min equilibrium period no significant changes were observed for coronory flow, left ventricular pressure, phosphocreatine, $\beta$-ATP, and $\mathrm{pH}_{\mathrm{i}}$ in any group. There were no significant differences between control group and all treatment groups.

CONTROL GROUP

After $15 \mathrm{~min}$ of ischaemia and $30 \mathrm{~min}$ of reperfusion, coronary flow, left ventricular pressure, phosphocreatine and $\beta$-ATP gradually recovered to 43(SEM 4)\%, 42(5)\%, $67(8) \%$, and $48(7) \%$, respectively (figs $2-5$ ).

PREISCHAEMIC ADMINISTRATION OF BRADYKININ (BK-PRE)

After 30 min of preischaemic treatment with bradykinin, the absolute values of coronary flow and left ventricular pressure in BK-pre group were significantly increased compared to the equilibrium period and to control $(P<0.05)$.

After $15 \mathrm{~min}$ of ischaemia and $30 \mathrm{~min}$ of reperfusion, percent recovery of coronary flow [71(5)\% v 43(4)\%, $\mathrm{P}<0.05]$, left ventricular pressure $[81(8) \% \quad v \quad 42(5) \%$, $\mathrm{P}<0.05]$, phosphocreatine [105(4)\% v 67(8)\%, $\mathrm{P}<0.05]$, and $\beta$-ATP[78(9)\% $v 48(7) \%, \mathrm{P}<0.05]$ was significantly improved in BK-pre compared to control. Recovery from

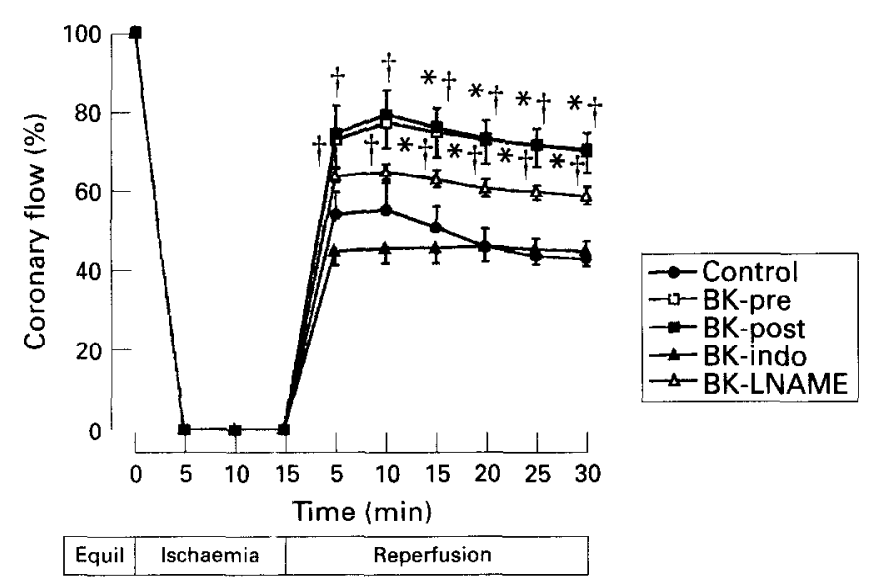

Figure 2 Relative changes of coronary flow during ischaemia and reperfusion in control $(n=8)$, and with preischaemic administration of bradykinin (BK-pre, $n=6)$, postischaemic administration of bradykinin (BK-post, $n=6)$, simultaneous administration of bradykinin and indomethacin ( $B K$-indo, $n=6$ ), and simultaneous administration of bradykinin and L-NAME $(B K-L N \Lambda M E, n=7)$ in rat hearts.

$* P<0.05$ v control $; \uparrow P<0.05$ v $B K$-indo. intracellular acidosis, as assessed by $\mathrm{pH}_{\mathrm{i}}$, was not different between $\mathrm{BK}$-pre and control (figs 2-5).

POSTISCHAEMIC ADMINISTRATION OF BRADYKININ (BK-POST) Preischaemic values of coronary flow and left ventricular pressure were not different between BK-post and control. After $15 \mathrm{~min}$ of ischaemia and $30 \mathrm{~min}$ reperfusion, percent recovery of coronary flow [71(4)\% v 43(4)\%, $\mathrm{P}<0.05]$ and left ventricular pressure [78(4)\% v 42(5)\%, $\mathrm{P}<0.05]$ was improved in BK-post compared to control. However, recovery of phosphocreatine $[70(4) \% \vee 67(8) \%, \mathrm{NS}]$ and $\beta$-ATP $[58(2) \%$ v 48(7)\%, NS] was similar. There was no difference for recovery of coronary flow $[71(5) \% v$ $71(4) \%, N S]$ and left ventricular pressure $[81(8) \% \vee 78(4) \%$, NS] between BK-pre and BK-post. However, recovery of phosphocreatine [105(4)\% $\%$ 70(4)\%, $\mathrm{P}<0.05]$ and $\beta$-ATP $[78(9) \%$ v 58(2)\%, P<0.05] was improved with BK-pre (figs 2-5).

PREISCHAEMIC ADMINISTRATION OF INDOMETHACIN (INDO) Preischaemic values of coronary flow and lett ventricular pressure were not different between Indo and control. After $15 \mathrm{~min}$ of ischaemia and $30 \mathrm{~min}$ reperfusion, percent recovery of coronary flow $[51(3) \% \vee 43(4) \%$, NS] and left

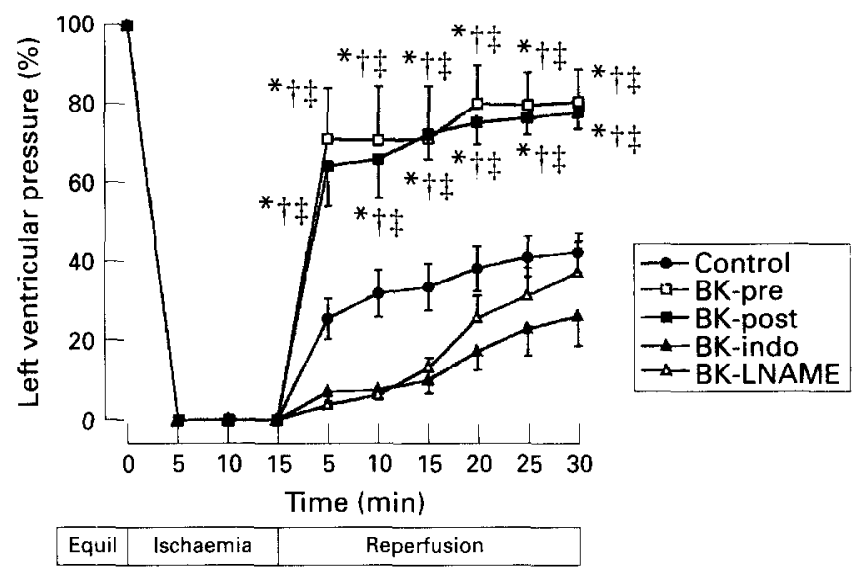

Figure 3 Relative changes of left ventricular developed pressure during ischaemia and reperfusion in control $(n=8)$, and with preischaemic administration of bradykinin (BK-pre, $n=6)$, postischaemic administration of bradykinin (BK-post, $n=6$ ), simultaneous administration of bradykinin and indomethacin (BK-indo. $n=6$ ), and simultaneous administration of bradykinin and $L-N A M E$ $(B K-L N A M E, n=7)$ in rats hearts.

$* P<0.05$ v control; $\dagger P<0.05 \vee B K$-indo; $\ddagger P<0.05 \vee B K$ LNAME. 


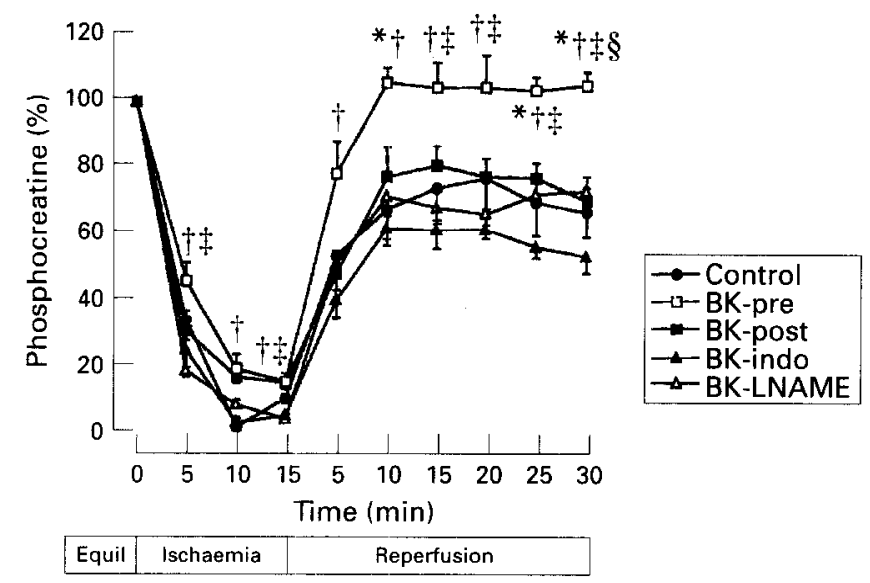

Figure 4 Relative changes of phosphocreatine during ischaemia and reperfusion in control $(n=8)$, and with preischaemic administration of bradykinin (BK-pre, $n=6$ ), postischaemic administration of bradykinin (BK-post, $n=6$ ), simultaneous administration of bradykinin and indomethacin (BK-indo, $n=6)$, and simultaneous administration of bradykinin and L-NAME (BKLNAME, $n=7$ ) in rat hearts.

${ }^{*} P<0.05$ v control; $\dagger P<0.05 \vee B K$-indo; $\ddagger P<0.05 \vee B K$ LNAME; $\$ P<0.05 \vee$ BK-post.

ventricular pressure $[48(8) \% \vee 42(5) \%$, NS] was similar to control (figs 2-5).

SIMULTANEOUS ADMINISTRATION OF BRADYKININ AND INDOMETHACIN (BK-INDO)

Preischaemic values of coronary flow showed a nonsignificant trend to be increased in BK-indo compared to control. However, preischaemic values of left ventricular pressure were higher in BK-indo than in control. $(\mathrm{P}<0.05)$.

After $15 \mathrm{~min}$ of ischaemia and $30 \mathrm{~min}$ reperfusion, recovery of coronary flow [45(4)\% v 43(4)\%, NS], left ventricular pressure $[29(9) \%$ v $42(5) \%$, NS], phosphocreatine $[53(5) \% v 67(8) \%, \mathrm{NS}]$, and $\beta$-ATP $[38(4) \% v$ $48(7) \%$, NS] with BK-indo was not different from control. Thus the improvement of recovery with bradykinin was

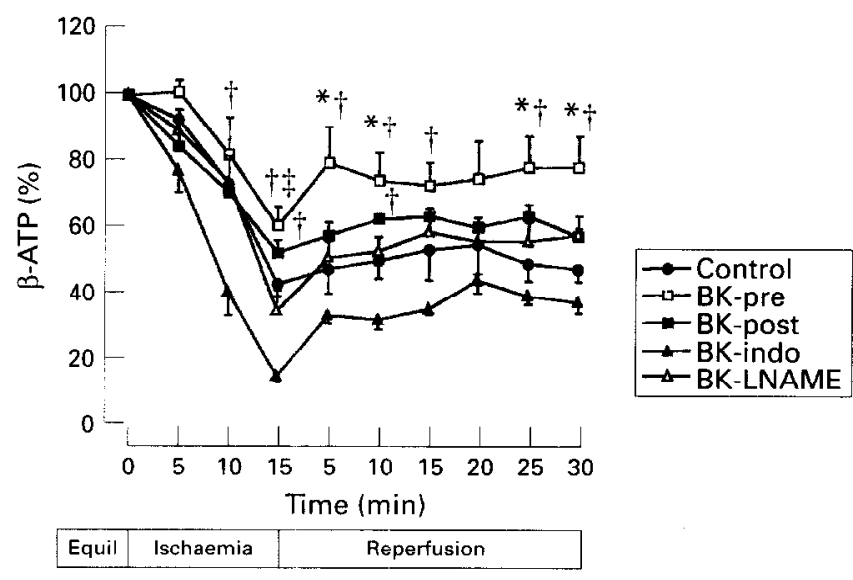

Figure 5 Relative changes of adenosine triphosphate ( $\beta$-ATP) during ischaemia and reperfusion in control $(n=8)$, and with preischaemic administration of bradykinin (BK-pre, $n=6)$, postischaemic administration of bradykinin (BK-post, $n=6$ ), simultaneous administration of bradykinin and indomethacin (BK-indo, $n=6$ ), and simultaneous administration of bradykinin and L-NAME $(B K-L N A M E, n=7)$ in rat hearts.

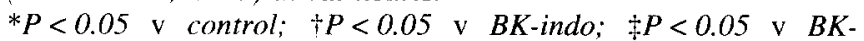
LNAME.

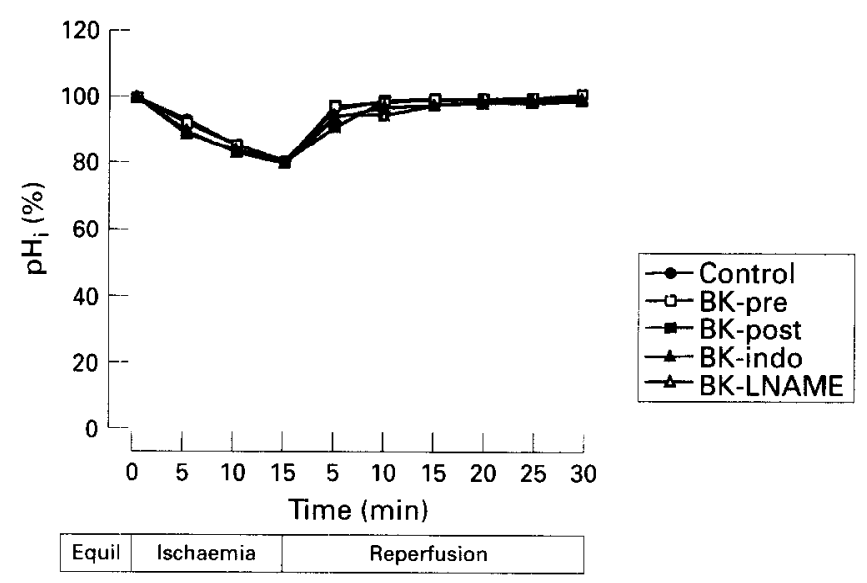

Figure 6 Relative changes of intracellular $p H\left(p H_{i}\right)$ during ischaemia and reperfusion in control $(n=8)$, and with preischaemic administration of bradykinin (BK-pre, $n=6)$, postischaemic administration of bradykinin (BK-post, $n=6$ ), simultaneous administration of bradykinin and indomethacin (BK-indo, $n=6)$, and simultaneous administration of bradykinin and L-NAME (BKLNAME, $n=7$ ) in rat hearts.

totally abolished with the combination of bradykinin and indomethacin (figs 2-5).

PREISCHAEMIC ADMINISTRATION OF L-NAME (L-NAME)

Preischaemic administration of L-NAME caused a significant decrease of coronary flow, but left ventricular pressure remained unchanged.

After $15 \mathrm{~min}$ of ischaemia and $30 \mathrm{~min}$ reperfusion, percent recovery of left ventricular pressure was $23(6) \%$ (NS $v$ control). Percent recovery of coronary flow was higher than in control $(\mathrm{P}<0.05)$, but absolute values $\left[3.8(0.2) \mathrm{ml} \cdot \mathrm{min}^{-1}\right]$ indicated a persistent low flow ischaemia (figs $2-5$ ).

SIMULTANEOUS ADMINISTRATION OF BRADYKININ AND L-NAME (BK-LNAME)

Preischaemic values of coronary flow with BK-LNAME were not different from control. However, a slight increase in left ventricular pressure $(\mathrm{P}<0.05)$ was observed.

After $15 \mathrm{~min}$ of ischaemia and $30 \mathrm{~min}$ reperfusion, recovery of coronary flow $[59(2) \% v 43(4) \%$, NS], left ventricular pressure $[40(9) \%$ v 42(5)\%, NS], phosphocreatine $[73(4) \% \vee 67(8) \%$, NS], B-ATP [58(6)\% $v 48(7) \%$, $\mathrm{NS}]$, and $\mathrm{pH}_{\mathrm{i}}[99(0.4) \% \vee 99(0.4) \%$, NS] with BK-LNAME were not different from control. Thus the improvement of recovery with bradykinin was totally abolished with the combination of bradykinin and L-NAME (figs 2-5).

\section{Discussion}

In the present study, we first show that bradykinin administration during reperfusion improves the recovery of coronary flow and myocardial performance; second that high energy phosphate compounds are not directly involved in the protective effect of bradykinin; and third that bradykinininduced release of nitric oxide and probably prostacyclin mediate the protective effect of bradykinin.

Evidence for the first finding arises from the improved recovery of coronary flow and left ventricular pressure after postischaemic administration of bradykinin. In the present study, the effect of bradykinin on the postischaemic recovery was compared when bradykinin was given before ischaemia and exclusively after ischaemia, starting with reperfusion. 
Both BK-pre and BK-post improved the postischaemic recovery of coronary flow and myocardial performance. It has previously been reported that preischaemic administration of bradykinin significantly reduced myocardial infarct size in the canine and rabbit model. ${ }^{67}$ Increased coronary flow, reduced enzymatic activities, a decreased incidence and duration of postischaemic reperfusion arrhythmias, and improved cardiodynamic indices in isolated rat hearts were also reported. ${ }^{18} 19$ In a pig model, bradykinin improved electrical stability two weeks after experimental myocardial infarction..$^{20}$ However, in all these previous studies bradykinin was given before the onset of ischaemia.

Our results strongly support the hypothesis that bradykinin has protective effects on ischaemic and reperfused hearts.

Second, we showed that high energy phosphate compounds are not directly related to the protective effect of bradykinin. In our study, an improved postischaemic recovery of mechanical performance concomitant with preservation of high energy phosphate compounds following preischaemic administration of bradykinin was observed. In contrast postischaemic administration of bradykinin resulted in an improved recovery of mechanical performance and coronary flow while the recovery of the high energy phosphate compounds was not different from control hearts. Therefore the cardioprotective effect of bradykinin was not directly related to the preservation of the high energy phosphate compounds. Some investigators previously proposed that an improvement of energy metabolism in ischaemic hearts may contribute to protective effects of bradykinin in the ischaemic heart. Following ischaemia and reperfusion, myocardial tissue levels of glycogen, ATP, and creatine phosphate were increased in bradykinin pretreated isolated rat hearts. ${ }^{518}$ Our results in BK-pre group correspond very well with previously published data. ${ }^{27}$ However, postischaemic administration of bradykinin resulted in an improved recovery of mechanical performance and coronary flow, while the recovery of the high energy phosphate compounds was not different from control hearts. Because of this discrepancy we speculate that the impaired breakdown of high energy phosphate compounds during ischaemia, when bradykinin is given preischaemically, may not be critical for the bradykinin related improvement of postischaemic recovery. On the other hand, in BK-indo and BK-LNAME there was faster depletion of ATP during ischaemia compared to BK-pre, suggesting that an unrestrained action of both nitric oxide (NO) and prostacyclin may contribute to the protective effect of bradykinin on ATP during ischaemia.

Third, we showed that bradykinin-induced release of a cyclooxygenase product, probably prostacyclin, mediated the protective effect. Evidence for this finding arises from the results that administration of indomethacin alone did not change the postischaemic recovery but simultaneous administration of bradykinin and indomethacin completely abolished the beneficial effect of bradykinin on the recovery of coronary flow, left ventricular pressure, phosphocreatine, and $\beta$-ATP in ischaemic hearts. Consequently the recovery of these variables did not differ significantly from control but did differ from BK-pre. Some investigators previously proposed that the beneficial effect of bradykinin in myocardial ischaemia is probably mediated by stimulation of endothelial $B_{2}$ receptors. This results in an increase in the intracellular calcium concentration and in the release of prostacyclin. ${ }^{6}$ The ability of bradykinin to stimulate prostacyclin generation from cultured endothelial cells is well recognised ${ }^{25}$ and this effect was inhibited in a dose dependent manner by the bradykinin receptor antagonist. ${ }^{26}$ Prostacyclin given to isolated working rat hearts reduced ischaemia-reperfusion injury. ${ }^{27}$ Our results support these observations. It is suggested that cyclooxygenase products, probably prostacyclin, are important mediators involved in the protective effects of bradykinin on ischaemic hearts. Thus bradykinin-induced release of vasodilator cyclooxygenase products contributes to the cardioprotective effects of bradykinin.

In addition, we showed that bradykinin-induced release of NO mediated the protective effect of bradykinin. Evidence for this arises from the finding that administration of L-NAME alone worsened the postischaemic recovery, and simultaneous administration of bradykinin and L-NAME abolished the beneficial effect of bradykinin on the recovery of coronary flow, left ventricular pressure, phosphocreatine, and $\beta$-ATP, which did not differ from control. Previous studies have shown that bradykinin is a potent endothelium dependent vasodilator in many vessels. ${ }^{21}$ It can stimulate the release of NO from cultured endothelial cells ${ }^{22}$ as well as from isolated guinea pig hearts. ${ }^{23}$ NO released from endothelial cells activates the haem protein soluble guanylyl cyclase in vascular smooth muscle cells and in platelets. The resulting increase in cyclic guanosine monophosphate inhibits smooth muscle contraction and platelet activation by reducing the intracellular concentration of free calcium. A recent study showed that this effect was blocked by the bradykinin $\mathrm{B}_{2}$ antagonist HOE140. ${ }^{24}$ In the present study, the improved postischaemic recovery of coronary flow reflects the dilator action of bradykinin, and the improved recovery of left ventricular pressure may result from the improved tissue perfusion. With simultaneous administration of bradykinin and L-NAME the bencficial effects of bradykinin on recovery of coronary flow, left ventricular pressure, phosphocreatine, and $\beta$-ATP in ischaemic hearts were abolished. Therefore an unrestrained action of nitric oxide contributes to the cardioprotective effect of bradykinin.

Our conclusions are: (1) bradykinin improves postischaemic myocardial recovery when given before ischaemia or starting with reperfusion; (2) this beneficial effect is only partially related to the preservation of the high energy phosphate compounds; and (3) the beneficial effects of bradykinin on postischaemic myocardial recovery are dependent from an unrestrained action of nitrix oxide and prostacyclin.

$\mathrm{PZ}$ is supported by the Swiss Foundation for Cardiology. CEZ is supported by a grant from Swiss National Science Foundation. PTB is a recipient of a career development grant (SCORE) from the Swiss National Science Foundation.

Key terms: ischaemia; reperfusion; myocardium; bradykinin; nitric oxide; prostacyclin; magnetic resonance spectroscopy; cardioprotective effect.

Received 8 August 1994; accepted 20 December 1994. Time for primary review 28 days.

1 Schölkens BA, Linz W. Cardioprotective effects of ACE inhibitors: experimental proof and clinical perspectives. Clin Physiol Biochem 1990;8(suppl I):33-43.

2 Gavras I, Gavras H. Cardioprotective potential of angiotensinconverting enzyme inhibitors. Clin Cardiol 1991;14(suppl IV): IV-68-71.

3 Ondetti MA, Cushman D. Enzymes of the renin-angiotensin system and their inhibitions. Annu Rev Biochem 1982;51: 283-308.

4 Westlin W, Mullane K. Does captopril attenuate reperfusioninduced myocardial dysfunction by scavenging free radicals? Circulation 1988;77(suppl I):30-9. 
5 Linz W, Schölkens BA, Influence of local converting enzyme inhibition on angiotensin and bradykinin effects in ischemic rat hearts. I Cardiovasc Pharmacol 1987;10(suppl VII): S75-82.

6 Linz W, Schölkens BA. Role of bradykinin in the cardiac effects of angiotensin-converting enzyme inhibitors. $J$ Cardiovasc Pharmacol 1992;20(suppl IX):S81-90.

7 Hartman JC, Wall TM, Hullinger TG, Shebuski RJ. Reduction of myocardial infarct size in rabbits by ramiprilat: reversal by the bradykinin antagonist HOE 140. J Cardiovasc Pharmacol 1993; 21:996-1003.

8 Müller-Esterl W. Kininogens, kinins, and kinships. J Cardiovasc Pharmacol 1990;15(suppl VI):S1-6.

9 Matsuki T, Yoshida S. Sympathetically induced myocardial ischaemia causes the heart to release plasma kinin. Cardiovasc Res 1987:21:428-32.

10 Baumgarten CR, Linz W, Kunkel G, Schölkens BA, Wiemer G. Ramiprilat increases bradykinin outflow from isolated hearts of rat. Br J Pharmacol 1993;108:293-5.

11 Hashimoto K, Hamamoto $\mathrm{H}$, Honda $\mathrm{Y}$, Hirose M, Furukawa S, Kimura E. Changes in components of kinin system and hemodynamics in acute myocardial infarction. Am Heart $J$ 1978;95:619-26.

12 Buser PT, Wagner S, Wu ST, et al. Verapamil preserves myocardial performance and energy metabolism in left ventricular hypertrophy following ischemia and reperfusion: phosphorus 31 magnetic resonance spectroscopy study. Circulation 1989;80: $1837-45$.

13 Zaugg CE, Zhu P, Simper D, Lüscher TF, Allegrini PR, Buser PT. Differential effects of endothelin- 1 on normal and postischemic reperfused myocardium. J Cardiovasc Pharmacol 1993;22(suppl VIII):S367-70

14 Buser PT, Wagner S, Wu S, Higgins CB, Wikman-Coffelt J. Protective effects of calcium antagonists on energy and substrate metabolism during ischemia and reperfusion. $J$ Cardiovasc Pharmacol 1991;18(suppl X):S87-92.

15 Buser PT, Auffermann W, Wu ST, Jasmin G, Parmley WW, Wikman-Coffelt J. Dobutamine potentiates amrinone's beneficial effects in moderate but not in advanced heart failure: ${ }^{31} \mathrm{P}-\mathrm{MRS}$ in isolated hamster hearts. Circ Res 1990;66:747-53.
16 Buser PT, Wikman-Coffelt J, Wu ST, Derugin N, Parmley WW, Higgins CB. Postischemic recovery of mechanical performance and energy metabolism in the presence of left ventricular hypertrophy: a ${ }^{31}$ p-MRS study. Circ Res 1990;66:735-46.

17 Gaddian DG, Radda GK, Richards RE, Seeley PJ. Biological applications of magnetic resonance. New York: Academic Press, 1979.

18 Linz W, Martorana PA, Schölkens BA. Local inhibition of bradykinin degradation in ischemic hearts. $J$ Cardiovasc Pharmacol 1990;15(suppl VI):S99-109.

19 Chahine R, Adam A, Yamaguchi N, Gaspo R, Regoli D, Nadeau R. Protective effects of bradykinin on the ischemic heart: implication of the $\mathrm{B}_{1}$ receptor. $\mathrm{Br} J$ Pharmacol 1993;108: 318-22.

20 Tobe TJ, de LC, Tio RA, Bel KJ, Mook PH, Wesseling H. In vivo effect of bradykinin during ischemia and reperfusion: improved electrical stability two weeks after myocardial infarction in the pig. J Cardiovasc Pharmacol 1991;17:600-7.

21 I eipert B, Becker BF, Gerlach E. Different endothelial mechanisms involved in coronary responses to known vasodilators. $A m J$ Physiol 1992;262:H1676-83.

22 Palmer RMJ, Ferrige AG. Nitric oxide release accounts for the biological activity of endothelium-derived relaxing factor. Nature 1987;327:524-6.

23 Kelm M, Schrader J. Control of coronary vascular tone by nitric oxide. Circ Res 1990;66:1561-75.

24 Wiemer G, Schölkens BA, Becker RHA, Busse R. Ramiprilat enhances endothelial autacoid formation by inhibiting breakdown of endothelium-derived bradykinin. Hypertension 1991;18:558-63.

25 McIntyre TM, Zimmerman GA, S.M. P. Cultured endothelial cells synthesize both platelet-activating factor and prostacyclin in response to histamine, bradykinin and adenosine triphosphate. $J$ Clin Invest 1985;76:271-80.

26 Hoffmann G, Pietsch R. Converting enzyme inhibition and vascular prostacyclin synthesis: effect of kinin receptor antagonism. Eur J Pharmacol 1990;178:79-83.

27 Linz W, Martorana PA, Grötsch H, Bei-Yin Q. Antagonizing bradykinin obliterates the cardioprotective effects of bradykinin and angiotensin-converting enzyme (ACE) inhibitors in ischemic hearts. Drug Dev Res 1990;19:393-408. 